\title{
Circulating tumour cells as biomarkers for evaluating cryosurgery on unresectable hepatocellular carcinoma
}

\author{
JIAN SHI $^{1}$, YUAN LI ${ }^{2}$, SHUZHEN LIANG $^{2}$, JIANYING ZENG ${ }^{2}$, GUIFENG LIU $^{2}$, FENG MU $^{2}$,

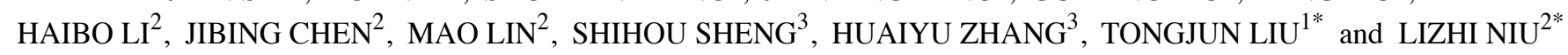 \\ ${ }^{1}$ Department of General Surgery, The Second Hospital of Jilin University, Changchun, Jilin 130041; \\ ${ }^{2}$ Fuda Cancer Hospital, Jinan University School of Medicine, Guangzhou Fuda Cancer Institute, \\ Guangzhou, Guangdong 510665; ${ }^{3}$ Department of Gastrointestinal, Colorectal and Anal Surgery, \\ China-Japan Union Hospital of Jilin University, Changchun, Jilin 130033, P.R. China
}

Received February 18, 2016; Accepted March 30, 2016

DOI: 10.3892/or.2016.5050

\begin{abstract}
We evaluated the efficacy of pre-cryosurgery and post-cryosurgery circulating tumour cells (CTCs) as biomarkers for unresectable hepatocellular carcinoma (HCC). Real-time qPCR was used to detect potential biomarker genes in CTCs, and magnetic-activated cell sorting (MACS) and fluorescence-activated cell sorting (FACS) was performed on 47 patients with hepatocellular cancer who underwent cryosurgery. CTCs in the 47 patients were assessed 1 day before cryosurgery, and 7 and 30 days after cryosurgery. The number of CTCs was $17.70 \pm 5.725,14.64 \pm 6.761$ and $10.28 \pm 5.598$, respectively, and this decreased significantly over time $(\mathrm{P}<0.01) . \Delta \mathrm{Ct}$ values for MAGE-3, survivin and carcinoembryonic antigen (CEA) were elevated significantly compared with those obtained before cryosurgery; $2^{-\Delta \Delta \mathrm{Ct}}$ values were $<1$ before cryosurgery, and were $0.63 \pm 1.56,0.21 \pm 0.22$ and $0.22 \pm 0.34$ for MAGE-3, survivin and CEA, respectively, at 7 days after treatment. At 30 days after treatment, $2^{-\Delta \Delta C t}$ values for MAGE-3, survivin and CEA were $0.24 \pm 0.82$, $0.03 \pm 0.07$ and $0.02 \pm 0.08$, indicating that gene expression in CTCs significantly decreased over time $(\mathrm{P}<0.01)$. CTCs were
\end{abstract}

Correspondence to: Dr Tongjun Liu, Department of General Surgery, The Second Hospital of Jilin University, No.218 Ziqiang Street, Nanguan District, Changchun, Jilin 130041, P.R. China E-mail: tongjunliu@163.com

Dr Lizhi Niu, Fuda Cancer Hospital, Jinan University School of Medicine, Guangzhou Fuda Cancer Inistitute, No.2 Tangde Road, Tianhe District, Guangzhou, Guangdong 510665, P.R. China

E-mail: fudaclab@gmail.com

*Contributed equally

Key words: hepatocellular carcinoma, cryosurgery, circulating tumour cells, reverse transcriptase polymerase chain reaction, flow cytometry useful biomarkers for evaluating the efficacy of cryosurgery on unresectable HCC.

\section{Introduction}

Hepatocellular carcinoma (HCC) is the third most common cause of cancer-related deaths worldwide. Approximately $70-80 \%$ of HCC patients are diagnosed at an advanced stage, $80 \%$ of whom have underlying cirrhosis and only $20-30 \%$ of these were able to undergo surgical resection (1). Patients presenting with advanced or unresectable disease have a very poor prognosis, with only $12 \%$ surviving for 5-years (2). An inability to diagnose during the early stages and insufficient therapeutic intervention results in most $\mathrm{HCC}$ patients progressing to metastasis, and the median survival is only a few months (3). Local ablation therapies are now deployed to treat advanced cases, including percutaneous ethanol injection, radiofrequency ablation (RFA), cryoablation, laser treatment, high-intensity focused ultrasound and microwave treatment (4). Argon-helium cryotherapy is also an effective local ablation therapy that has been used to treat HCC (5). Compared with RFA and other thermal ablation techniques, cryoablation can inflict greater damage on tumour tissues and result in more clearly discernible treatment areas, and can suppress ectopic tumours (6).

Recurrence following treatment in advanced HCC patients cannot always be prevented, and while the treatments listed above have decreased mortality, drug resistance and tumour recurrence are common and remain to be addressed (7). The most important factor contributing to poor prognosis is the inability to diagnose the disease early, and identification of sensitive, robust circulating biomarkers is critical. Circulating tumour cells (CTCs) are cancer cells that are shed from either the primary tumour or its metastases and that circulate in the peripheral blood. While metastases are directly responsible for the majority of cancer deaths, CTCs may constitute seeds for metastases and may indicate the spread of the disease $(8,9)$. CTCs are increasingly evaluated in liquid biopsies, and their analysis holds great promise for identification of patients at high-risk of relapse, for determining specific adjuvant therapies for individual patients, and for monitoring responses 
to treatments (10-12). Counting the number of CTCs proved to be an independent prognostic biomarker in small cell and non-small cell lung cancer patients $(13,14)$, and in otherepithelial cell-derived tumours such as breast $(15,16)$, colorectal (17), and prostate cancer (18). CTCs are often present in the blood of patients suffering metastasis, and detection in peripheral blood is highly correlated with early tumour metastases (19). CTCs can also provide information on tumour biological activity and can facilitate the real-time prediction of prognosis in patients suffering distant metastases $(17,18,20)$. The purpose of the present study was to use immune magnetic bead flow cytometry and real-time qPCR to measure the number of CTCs in the peripheral blood of HCC patients before and after cryosurgery and to correlate with disease prognosis.

\section{Materials and methods}

Patients. Patients with hepatocellular cancer were recruited from the Fuda Cancer Hospital of Jinan University between June 2014 and June 2015, and all accepted cryoablation therapy. Inclusion and exclusion criteria were as follows:

Inclusion criteria: examined by imaging and clinical TNM stage III or IV; diagnosed by pathological examination as malignant hepatocellular cancer; accepted cryosurgery in our hospital to target local tumours, metastasis and tumour recurrence in situ; voluntary consent was obtained; post-treatment survival estimated at $>3$ months; age $>18$ and $<85$; Karnofsky performance status (KPS) score $>60$ points; routine blood, liver and kidney function.

Exclusion criteria: local and/or systemic chemotherapy ongoing, or finished no more than 15 days before experiments; blood coagulation disorders or severe anaemia; merging into other primary tumours; concurrent venereal disease, leprosy, AIDS or HIV infection, hepatitis, tuberculosis, blood parasites or other infectious diseases.

In total, 47 patients with HCC met the above criteria (Table I) and provided written consent. The present study was approved by the Ethics Committee of Fuda Cancer Hospital. Peripheral blood $(17 \mathrm{ml})$ was collected at 3 time points using ACD vacuum tubes (Becton-Dickinson and Co., Franklin Lakes, NJ, USA) at 1 day before cryoablation, and at 7 and 30 days after the operation.

Percutaneous cryoablation. Comprehensive cryoablation was performed on all 47 patients. Percutaneous cryoablation was performed under double-row helical computed tomography (SOMATOM Emotion Duo; Siemens, Munich, Germany) or color ultrasound (ALOKA-SSD-5500A; Aloka, Tokyo, Japan) guidance. All cryosurgery was performed by Lizhi Niu and assistants (Haibo $\mathrm{Li}$ and Feng $\mathrm{Mu}$ ). Each procedure comprised 1-3 freeze/thaw cycles accomplished using an argon gas-based cryosurgical unit (Endocare Corp., Irvine, CA, USA) $(21,22)$. Depending on the location of the metastasis, probes were inserted percutaneously under ultrasound or CT guidance; 2 or $5 \mathrm{~mm}$ probes or rarely, $10 \mathrm{~mm}$ probes (Cryo-42; Endocare Corp.) were used according to the size of the tumour. Two or more probes were simultaneously used for large lesions. Individual tumours were frozen sequentially on a tumour by tumour basis. The duration of freezing depended on the formation of an 'ice ball' visible on ultrasonography as
Table I. Patient information and baseline CTC number.

\begin{tabular}{lcc}
\hline Group & $\mathrm{N}$ & $\begin{array}{c}\text { No. of CTCs 1 day } \\
\text { before surgery }\end{array}$ \\
\hline $\begin{array}{l}\text { Age (years) } \\
\leq 60\end{array}$ & 23 & $17.04 \pm 4.22$ \\
$>60$ & 24 & $18.33 \pm 5.73$ \\
Differentiation & & \\
$\quad$ High differentiation & 13 & $16.62 \pm 6.87$ \\
$\quad$ Medium/low differentiation & 34 & $17.70 \pm 5.73$ \\
Lymph node metastasis & & \\
$\quad$ Yes & 31 & $17.65 \pm 5.86$ \\
No & 16 & $17.81 \pm 5.65$ \\
Clinical stage & & \\
III & 17 & $17.00 \pm 6.36$ \\
IV & 30 & $18.10 \pm 5.40$ \\
\hline
\end{tabular}

CTC, circulating tumour cells.

a hypoechogenic area $>1 \mathrm{~cm}$ larger than the diameter of the lesion. Thawing was achieved by input of helium for a period of time equal to the freezing time before the next freezing process was begun.

Cell culture. HepG2 carcinoma cells obtained from Cell Resource Center (Institute of Basic Medical Sciences, Chinese Academy of Medical Sciences/Peking Union Medical College, Beijing, China) were maintained in Dulbecco's modified Eagle's medium containing $10 \%$ fetal calf serum at $37^{\circ} \mathrm{C}$ in a humidified atmosphere containing $5 \% \mathrm{CO}_{2}$.

Preparation of blood samples. Samples were stored at room temperature and processed within $6 \mathrm{~h}$ after collection. Approximately $20 \mathrm{ml}$ blood was drawn via vein puncture from each of the 47 HCC patients and from 10 healthy volunteers. Blood from healthy volunteers was used to plot a standard curve for low cytometric experiments. To avoid contamination with skin cells, $5 \mathrm{ml}$ blood was discarded before experimental samples were taken as previously described. Briefly, mononucleocytes were separated from other blood components using human peripheral blood lymphocyte separation liquid (Tianjin Haoyang Biological Manufacture Co., Ltd., Tianjin, China) and centrifugation at $1,800 \mathrm{x}$ g for $20 \mathrm{~min}$ at $4^{\circ} \mathrm{C}$. Interface cells were removed and washed, and RBCs were removed using BD Pharm Lyse ${ }^{\mathrm{TM}}$ (Becton-Dickinson, San Jose, CA, USA). Following further washes, mononuclear cells were counted and samples were divided into two for RT-PCR and multiparameter flow cytometric experiments (each sample contained at least $2-3 \times 10^{6}$ cells. Cell pellets were resuspended in phosphate-buffered saline (PBS) (Life Technologies, Shanghai, China) for multiparameter flow cytometry, then in TRIzol reagent following counting using a $\mathrm{TC} 0^{\mathrm{TM}}$ automatic cell count meter (Bio-Rad, Hercules, CA, USA). Viable cells were stained using trypan blue solution (Life Technologies, Carlsbad, CA, USA) and stored at $-70^{\circ} \mathrm{C}$ until needed for RNA extraction. 
Table II. Primers used to amplify CTC marker genes.

Primer name

MAGE-3-F

MAGE-3-F
MAGE-3-R

Survivin-F

Survivin-R

CEA-F

CEA-R

GADPH-F

GADPH-R
Primer sequence $\left(5^{\prime}-3^{\prime}\right)$

Product length (bp)

CTC, circulating tumour cells.

Flow cytometry. After separation of blood using human peripheral blood lymphocyte separation liquid, mononucleocytes were washed twice with sterile Hank's balanced salt solution (Life Technologies). Isolated cells were enriched by binding to magnetic CD326 (EpCAM) MicroBeads (Miltenyi Biotech Ltd., Bergisch Gladbach, Germany) using magneticactivated cell sorting (MACS). Enriched isolated cells were then labelled with monoclonal antibodies targeting epithelial cell antigens CD45, CD326 and cytokeratin 8, 18 and 19 (Miltenyi Biotech Ltd.) and incubated in the dark at room temperature for $12 \mathrm{~min}$. Antibodies specific for leukocytes (CD45) labelled with phycoerythrin (PE) $(10 \mu \mathrm{l})$, specific for epithelial cells (cytokeratin 8, 18 and 19) labelled with fluorescein isothiocyanate (FITC) $(10 \mu \mathrm{l})$ and specific for epithelial cells (CD326/Ep-CAM) labelled with allophycocyan (APC) (10 $\mu \mathrm{l})$ were added/7.5 ml whole blood. Cell pellets were resuspended in $500 \mu \mathrm{l}$ PBS and counted by flow cytometry using a BD FACSCanto ${ }^{\mathrm{TM}}$ II apparatus (Becton-Dickinson). Cells that were CD45-negative, CK- and CD326-positive were defined as CTCs.

Real-time $q P C R$. Primers for GAPDH and tumour markers survivin, MAGE-3 and CEA (Table II) have been reported previously (23-26), and were synthesized by the Shanghai Yingweijieji Corporation. RNA was extracted from frozen samples using $1 \mathrm{ml}$ TRIzol (Life Technologies). After thawing, $0.2 \mathrm{ml}$ chloroform (Guangzhou Chemical Reagent Factory, Guangzhou, China) was added and samples were centrifuged at $13,500 \mathrm{x} g$ for $15 \mathrm{~min}$ at $4^{\circ} \mathrm{C}$. Supernatants containing intact RNA were placed into fresh tubes, and RNA was precipitated with $500 \mu 1$ isopropyl alcohol washed with $75 \%$ ethanol (both from Tianjin Fuyu Fine Chemical Co., Ltd., Tianjin, China), and dissolved in $50 \mu \mathrm{l}$ RNase-free water. Using a Thermo Scientific Multiskan Go (Thermo Fisher, Shanghai, China), RNA concentration and purity were measured, and RNA was diluted to the required concentration. Amplifications were performed in 8-tube strips and subjected to one-step qPCR detection using SYBR-Green I following an initial reverse transcription step. Reactions $(20 \mu \mathrm{l})$ contained $10 \mu \mathrm{l}$ of $2 \mathrm{X}$ One-Step SYBR RT-PCR buffer 4, $0.8 \mu \mathrm{l}$ of PrimeScript Enzyme Mix 2 (both by Takara, Dalian, China), $0.8 \mu \mathrm{l}$ of $10 \mu \mathrm{M}$ upstream and downstream primers, $0.4 \mu \mathrm{l}$ of 50X ROX

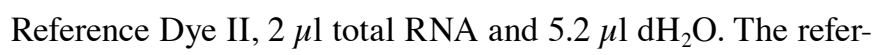
ence dye was used to record the fluorescence signal reaching the threshold cycle number $(\mathrm{Ct})$ as defined in the manufacturer's instructions (Life Technologies). Reactions were performed as follows: reverse transcription, $42^{\circ} \mathrm{C}$ for $5 \mathrm{~min}, 95^{\circ} \mathrm{C}$ for $10 \mathrm{sec}$; PCR, 40 cycles of $95^{\circ} \mathrm{C}$ for $5 \mathrm{sec}$ and $60^{\circ} \mathrm{C}$ for $34 \mathrm{sec}$; melting curve, $95^{\circ} \mathrm{C}$ for $15 \mathrm{sec}, 60^{\circ} \mathrm{C}$ for $1 \mathrm{~min}, 95^{\circ} \mathrm{C}$ for $15 \mathrm{sec}$. PCR experiments were stable, repeatable and did not suffer from non-specific amplification.

Statistical analysis. For PCR experiments, amplifications were performed twice with each primer pair, averaged and analysis was performed on triplicate data. PCR experiments yielded the threshold cycle number $(\mathrm{Ct})$ from the fluorescence signal based on the $\Delta \mathrm{Ct}$ method using the equation $\Delta \mathrm{Ct}=\mathrm{Ct}_{\text {Target gene }}-\mathrm{Ct}_{\mathrm{GADPH}}$. Expression was expressed relative to the GADPH internal standard. A lower $\Delta \mathrm{Ct}$ value indicates a higher level of expression. Gene expression was measured before and after cryotherapy using the $2^{-\Delta \Delta \mathrm{Ct}}$ method as previously described (27) as follows: $2^{-\Delta \Delta \mathrm{Ct}}=2^{-}\left(\Delta \mathrm{Ct}\right.$ post-cryosurgery $-\Delta^{\mathrm{Ct}}$ pre-cryosurgery). After adjusting GADPH gene expression to equal $1,2^{-\Delta \Delta \mathrm{Ct}}$ gave the level of gene expression relative to that before cryotherapy.

Data were analyzed using SPSS version 20.0 (IBM, Armonk, NY, USA) and expressed as means \pm SD. Random analysis of variance was performed and $\mathrm{P}<0.05$ was considered statistically significant, whereas $\mathrm{P}<0.01$ was considered statistically significant for expression differences. GraphPad Prism version 6.0 (GraphPad Software, Inc., San Diego, CA, USA) was used to plot all graphs.

\section{Results}

Flow cytometry. A standard curve was plotted using data from HepG2 cells from healthy volunteers, and serial dilution $(0.0001,0.001,0.005$ and $0.05 \%$ ) of human HepG2 tumour cells in volunteers blood established a lower detection limit of $0.001 \%$, equivalent to one cell/100,000 white blood cells (Fig. 1A-D). Below this level, background noise makes the signal unreliable. Recovery and linearity were highly reproducible across 3 separate experiments (Fig. 1E), and the number of tumour events recovered could be positively 

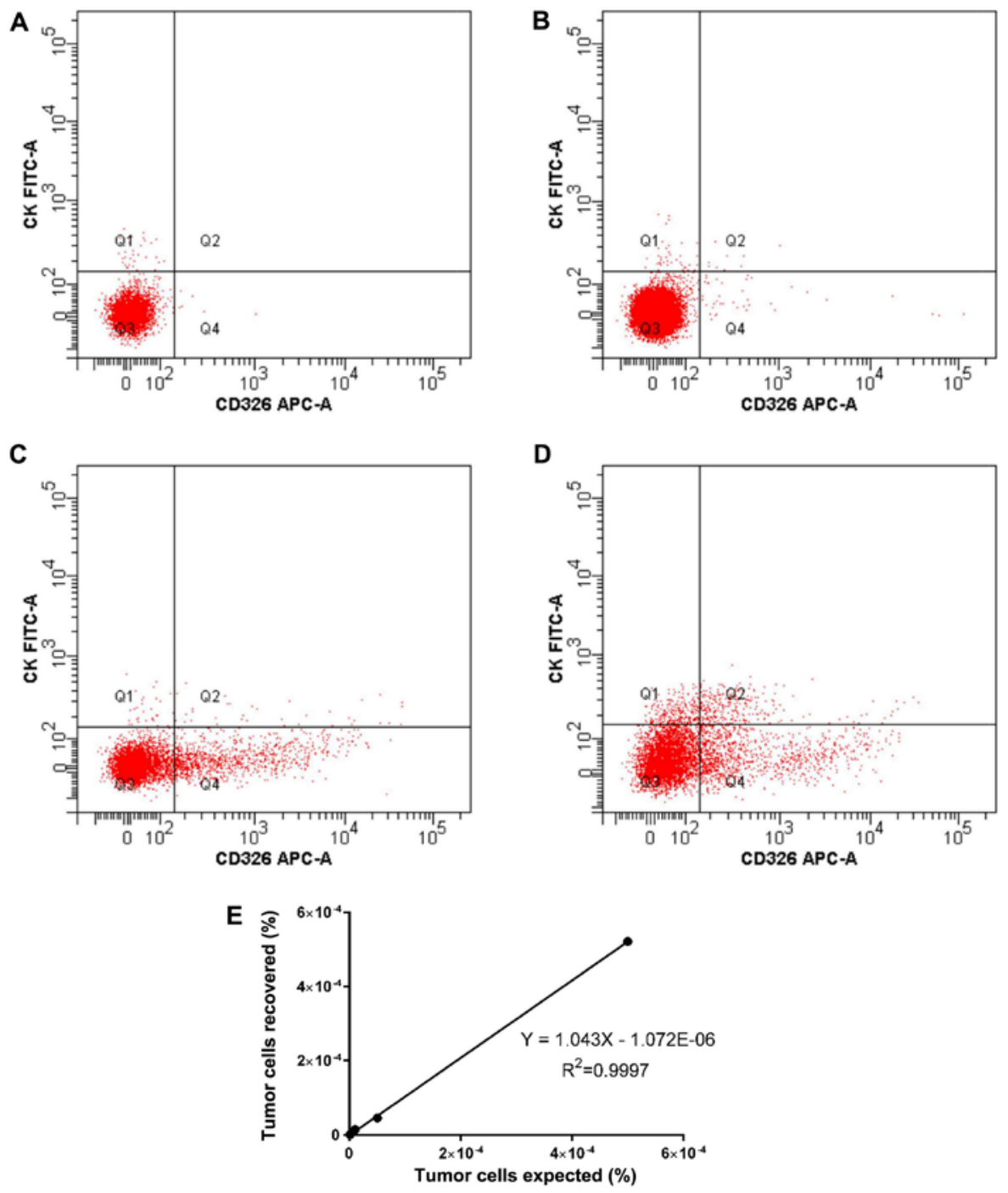

Figure 1. Flow cytometry of CTCs in the peripheral blood of patients before and after cryotherapy for unresectable hepatocellular carcinoma. (A-D) Analysis of serial dilutions $(0.0001,0.001,0.005$ and $0.05 \%)$ of human HepG2 tumour cells in normal human blood. (E) Recovery and linear relationship across 3 separate experiments.

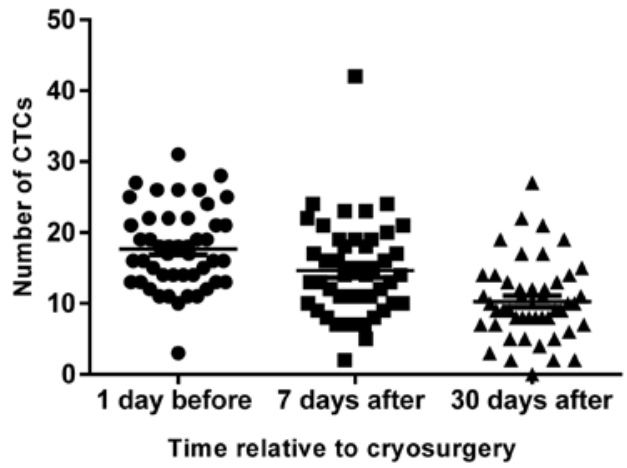

Figure 2. Number of CTCs in the peripheral blood of HCC patients before and after cryosurgery; $\mathrm{P}<0.01(\mathrm{n}=47)$.

correlated with the number of tumour events expected based on serial dilution $\left(\mathrm{R}^{2}=0.9998\right)$.

Peripheral blood CTCs from all the 47 patients was tested at 1 day before $\mathrm{HCC}$ cryosurgery, and at 7 and 30 days after surgery (Fig. 2). The number of CTCs at 1 day before surgery was set as the baseline and was $17.70 \pm 5.725$. The number of CTCs 7 and 30 days after surgery was $14.64 \pm 6.761$ and $10.28 \pm 5.598$, respectively. Random analysis of variance was performed using SPSS version 20.0, which demonstrated that the number of CTCs in peripheral blood decreased significantly after cryosurgery $(\mathrm{P}<0.01$; Table III).

\section{Real-time $q P C R$}

Changes in $\triangle C t$ following cryotherapy. In all 47 patients with locally advanced HCC, $\Delta \mathrm{Ct}$ values of CTCs were elevated following cryotherapy, which corresponded to a decrease in specific CTC tumour markers. This suggests cryotherapy can reduce the number of peripheral blood CTCs in HTC patients, which reduces the risk of tumour recurrence and metastasis.

After cryotherapy, expression of different tumour markers decreased by different amounts. The preoperative MAGE-3 $\Delta \mathrm{Ct}$ value was $5.71 \pm 5.17$, compared with a 7 -day postoperative rise to $8.65 \pm 5.41$, and a 30 -day postoperative rise to $11.37 \pm 5.50$. The preoperative survivin $\Delta \mathrm{Ct}$ value was $2.09 \pm 5.16$, compared with a 7 - and 30 -day postoperative 
Table III. Number of CTCs before and after cryosurgery.

\begin{tabular}{|c|c|c|c|}
\hline Patient ID & $\begin{array}{c}\text { No. of CTCs } \\
1 \text { day before } \\
\text { treatment }\end{array}$ & $\begin{array}{c}\text { No. of CTCs } \\
7 \text { days after } \\
\text { treatment }\end{array}$ & $\begin{array}{c}\text { No. of CTCs } \\
30 \text { days after } \\
\text { treatment }\end{array}$ \\
\hline $\mathrm{P} 1$ & 11 & 8 & 4 \\
\hline $\mathrm{P} 2$ & 13 & 15 & 9 \\
\hline P3 & 12 & 13 & 8 \\
\hline P4 & 22 & 14 & 11 \\
\hline P5 & 19 & 7 & 3 \\
\hline P6 & 11 & 10 & 9 \\
\hline P7 & 22 & 17 & 12 \\
\hline P8 & 10 & 5 & 2 \\
\hline P9 & 18 & 7 & 7 \\
\hline P10 & 15 & 19 & 11 \\
\hline P11 & 22 & 12 & 8 \\
\hline P12 & 15 & 9 & 5 \\
\hline P13 & 17 & 22 & 15 \\
\hline P14 & 18 & 21 & 9 \\
\hline P15 & 28 & 16 & 8 \\
\hline P16 & 16 & 13 & 19 \\
\hline P17 & 12 & 9 & 11 \\
\hline P18 & 14 & 16 & 13 \\
\hline P19 & 21 & 17 & 22 \\
\hline P20 & 13 & 15 & 8 \\
\hline P21 & 14 & 11 & 7 \\
\hline P22 & 26 & 18 & 21 \\
\hline $\mathrm{P} 23$ & 16 & 14 & 12 \\
\hline P24 & 25 & 23 & 27 \\
\hline P25 & 21 & 14 & 17 \\
\hline P26 & 21 & 11 & 9 \\
\hline P27 & 27 & 12 & 10 \\
\hline P28 & 16 & 8 & 11 \\
\hline P29 & 13 & 11 & 14 \\
\hline P30 & 14 & 7 & 5 \\
\hline P31 & 18 & 15 & 13 \\
\hline P32 & 26 & 16 & 17 \\
\hline P33 & 24 & 18 & 10 \\
\hline P34 & 17 & 19 & 8 \\
\hline P35 & 25 & 13 & 10 \\
\hline P36 & 14 & 10 & 9 \\
\hline P37 & 13 & 19 & 6 \\
\hline P38 & 16 & 10 & 12 \\
\hline P39 & 19 & 11 & 8 \\
\hline P40 & 11 & 7 & 2 \\
\hline P41 & 18 & 21 & 14 \\
\hline P42 & 31 & 42 & 19 \\
\hline P43 & 19 & 24 & 14 \\
\hline P44 & 3 & 2 & 0 \\
\hline P45 & 26 & 20 & 5 \\
\hline P46 & 11 & 23 & 2 \\
\hline P47 & 19 & 24 & 7 \\
\hline
\end{tabular}

CTCs, circulating tumour cells.

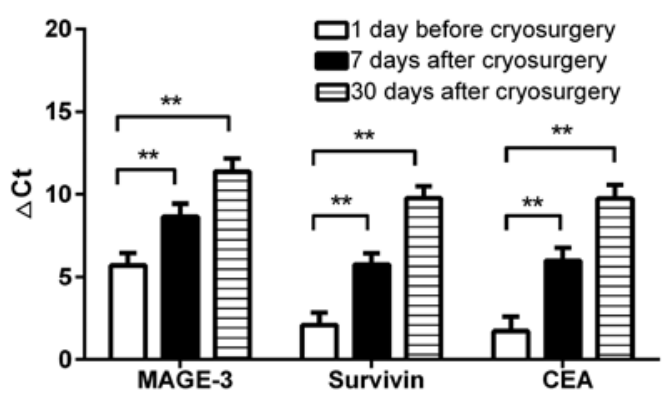

Figure $3 . \Delta \mathrm{Ct}$ values before and after cryosurgery; ${ }^{* *} \mathrm{P}<0.01(\mathrm{n}=47)$.

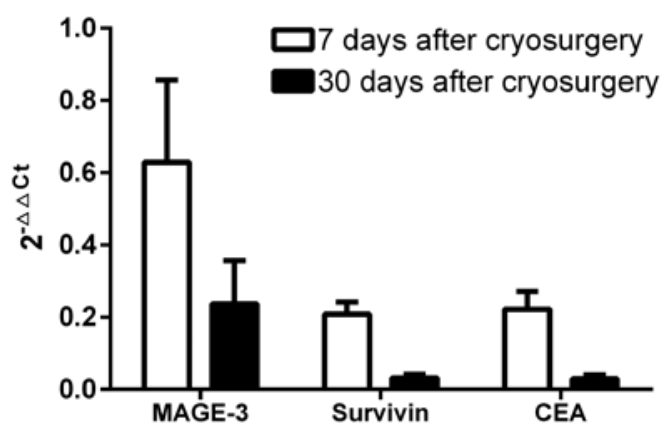

Figure 4. Expression of specific CTC markers before and after cryosurgery Expression changes were determined using the $2^{-\Delta \Delta \mathrm{Ct}}$ method.

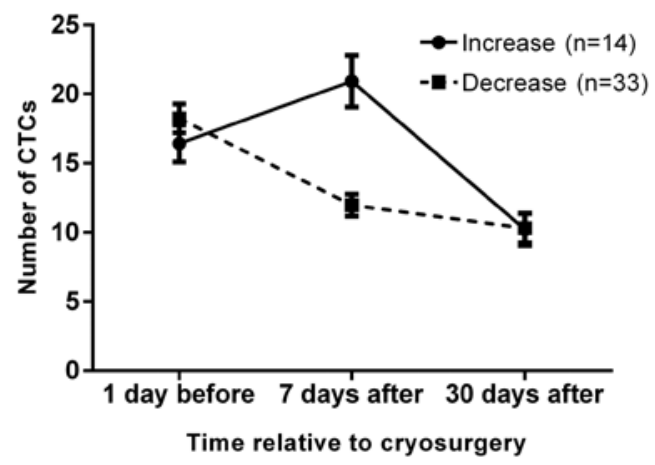

Figure 5. Changes in the number of CTCs in individual HCC patients 7 days after cryosurgery.

rise to $5.74 \pm 4.85$ and $9.77 \pm 5.02$, respectively. The CEA $\Delta \mathrm{Ct}$ value increased from a preoperative value of $1.73 \pm 5.99$, to a 7-day postoperative value of $5.98 \pm 5.36$, and a postoperative 30 -day value of $9.75 \pm 5.73$. Random analysis of variance using SPSS 17.0 showed that cryotherapy clearly increased the $\Delta \mathrm{Ct}$ value of CTC markers ( $\mathrm{P}<0.01$; Fig. 3 ).

Changes in $2^{-\Delta \Delta C t}$ following cryotherapy. Changes in $2^{-\Delta \Delta \mathrm{Ct}}$ values were assessed to determine gene expression before and after cryotherapy. MAGE-3 was $0.63 \pm 1.56$ and $0.24 \pm 0.82$ at 7 and 30 days after cryosurgery, respectively, compared with $0.21 \pm 0.22$ and $0.03 \pm 0.07$ for survivin, and $0.22 \pm 0.34$ and $0.02 \pm 0.08$ for CEA (Fig. 4). $2^{-\Delta \Delta \mathrm{Ct}}$ values correspond to the fold-change in relative gene expression, and since all postoperative values were $<1$, cryosurgery clearly decreased CTC markers, and the decrease was larger over time. 


\section{Discussion}

Hepatocellular carcinoma (HCC) is the third most common cause of cancer-related deaths worldwide. At present, tumour resection and liver transplantation are the most effective treatments $(28,29)$, but unresectable lesions are treated using ablation therapies such as percutaneous ethanol injection, radiofrequency ablation (RFA), cryoablation, laser treatment, high-intensity focused ultrasound and microwave treatment (4). Argon-helium cryotherapy has also been tested on HCC (5) and was shown to cause greater damage to tumour tissues (6). Additionally, treatment areas are more easily discernible, and the therapy can successfully suppress ectopic tumours. Although these treatments have decreased HCC mortality, recurrence in advanced HCC patients is common and difficult to prevent. Nowadays, serum AFP, a secretory protein, is widely used for diagnosing HCC patients and monitoring disease progression, but it has a sensitivity ranging from $39-97 \%$ and a specificity ranging from $76-95 \%$, even when used to screen high-risk populations (30-32). A more reliable biomarker is ideally needed in the clinic, a circulating tumour cells (CTCs) may provide a more sensitive and robust circulating biomarker. CTCs are cancer cells that have been shed from either the primary tumour or its metastases and that circulate in the peripheral blood. While metastases are directly responsible for the majority of cancer deaths, CTCs may constitute seeds for metastases and may indicate the spread of disease $(8,9)$.

CTCs in liquid biopsies can provide information on the risk of relapse, can help to determine which specific adjuvant therapies may be appropriate, and can be used to monitor responses to treatment (10-12). For advanced HCC patients with or without other organ metastasis, conventional treatments generally have little effect. Argon-helium knife cryoablation therapy is a novel local treatment that is minimally invasive, thus intraoperative complications such as bleeding and infection are less prevalent than in conventional surgery. However, as with conventional surgery, the risk of postoperative blood or lymphatic metastasis is high, and tumour recurrence, metastasis and ultimately death may result. Improving the survival and quality of life for patients with locally advanced disease remains a priority, and new methods for diagnosis and establishing prognosis are much needed.

Counting the number of CTCs may aid cancer diagnosis and help predict the likelihood of recurrence, and can also be used to monitor the effectiveness of postoperative radiotherapy and chemotherapy (33). Additionally, dynamic detection of peripheral blood CTCs is likely to become a reliable prognostic indicator for locally advanced hepatocellular cancer patients, and may help to quickly identify those with a high-risk of recurrence, thus improving survival rate and quality of life. The isolation and identification of CTCs have developed rapidly in recent years, and fluorescence-activated cell sorting (FACS) combined with magnetic-activated cell sorting (MACS) quantitatively analyzes and sort single cells and biological particles at the functional level. This technique can analyze thousands of cells at high speed, and can detect multiple parameters of a single cell simultaneously, which is a big advantage over conventional fluorescent approaches in terms of speed and precision. Flow cytometric detection of peripheral blood CTCs is dependent on the expression of tumour-specific markers such as cytokeratins (CKs) on the surface of epithelial cells. CKs are proteins that consist of keratin-containing intermediate filaments that form the intracytoplasmic cytoskeleton, and their expression primarily depends on the type of epithelia, the degree of terminal differentiation and the stage of development (34). In many cases, cytokeratin expression in tumours and peripheral blood has prognostic significance for cancer patients, and CK8/18/19 expression has been used as a biomarker for HCC histopathology $(35,36)$. In order to reduce the occurrence of false negatives, we used CD326 (EpCAM) as an additional specific marker for positive selection (37), and used CD45 for negative selection of leukocytes (38). Flow cytometry can then be used to detect double-positive CTCs (CD45, $\mathrm{CK}^{+}$and $\left.\mathrm{CD} 326^{+}\right)$. In the present study, we applied this method to detect peripheral blood CTCs in 47 patients with locally advanced HCC. After cryoablation therapy, the number of peripheral blood CTCs was markedly decreased $(\mathrm{P}<0.01)$, indicating potential usefulness for prognostic evaluation of cryosurgery. Although promising, at present there is no effective method for evaluating the surgical success of argon-helium knife cryoablation, and the results of the present study may provide a breakthrough in this area.

At 7 days after surgery, the number of CTCs in peripheral blood increased in 14/47 patients (29.79\%) compared with preoperative numbers, but all patients exhibited a marked decrease at 30 days after surgery (Fig. 5). This may be due to the large number of CTCs released into the blood during surgery and a delay in their removal by the immune system. The initial postoperative rise may be associated with immunity following cryoablation, since tumours release antigen that can lead to 'high zone tolerance' immunosuppression (39). This can reduce the ability of the immune system to recognise tumour cells, but immune enhancement could reverse this process to decrease CTCs by 30 days post-surgery (40).

RT-qPCR is a commonly used and effective method for measuring gene expression and detecting CTCs. This method is highly sensitive, quantitative, rapid, non-polluting and facilitates monitoring in real-time. RT-PCR also overcomes the high rate of false positives that can be a problem for traditional PCR-based methods. In the present study, we used an RT-qPCR method to measure expression of the reference gene GADPH, along with the metastasis-associated markers MAGE-3, survivin and CEA in CTCs from 47 locally advanced HCC patients before and after cryotherapy. The results showed that CTCs in peripheral blood decreased following cryosurgery $(\mathrm{P}<0.01)$, indicating a lower risk of tumour recurrence and metastasis following this type of therapeutic intervention. Patients expressing high levels of these CTC markers are likely to have poor prognosis with increased risk of recurrence and/or metastasis. Our method is therefore suitable for evaluation of cryotherapy.

Numerous tumour treatments involve local surgical excision of legions, and while initial results are often promising, recurrence and/or metastasis can occur, and eradication of all cancerous cells can be very difficult to achieve. Such as all existing cancer treatments, cryosurgery is not perfect, and changes in the immune system following surgery can influence the therapeutic outcome. Our results indicate that detection of CTCs in liquid biopsy experiments could help to determine whether cryosurgery is likely to be successful. In the future, detection of CTCs could conceivably replace radioscopy for 
early detection of cancers and/or re-examination following surgery and postoperative radiotherapy and chemotherapy.

\section{Acknowledgements}

All procedures performed in studies involving human participants were in accordance with the ethical standards of the Institutional and/or National Research Committee and with the 1964 Helsinki declaration and its later amendments or comparable ethical standards.

\section{References}

1. Hu KQ: Advances in clinical application of cryoablation therapy for hepatocellular carcinoma and metastatic liver tumor. J Clin Gastroenterol 48: 830-836, 2014.

2. Maluccio M and Covey A: Recent progress in understanding, diagnosing, and treating hepatocellular carcinoma. CA Cancer J Clin 62: 394-399, 2012.

3. Farazi PA and DePinho RA: The genetic and environmental basis of hepatocellular carcinoma. Discov Med 6: 182-186, 2006.

4. Lencioni R: Loco-regional treatment of hepatocellular carcinoma. Hepatology 52: 762-773, 2010.

5. Sheen AJ and Siriwardena AK: The end of cryotherapy for the treatment of nonresectable hepatic tumors? Ann Surg Oncol 12: 202-204, 2005

6. Hutchinson M, Shyn P and Silverman S: Cryoablation of Liver Tumors. In: Image-Guided Cancer Therapy. Dupuy DE, Fong Y and McMullen WN (eds). Springer New York, pp491-503, 2013. 10.1007/978-1-4419-0751-6_35.

7. Ling S, Tian Y, Zhang H, Jia K, Feng T, Sun D, Gao Z, Xu F, Hou Z, Li Y, et al: Metformin reverses multidrug resistance in human hepatocellular carcinoma Bel-7402/5-fluorouracil cells. Mol Med Rep 10: 2891-2897, 2014.

8. Alix-Panabières $\mathrm{C}$ and Pantel $\mathrm{K}$ : Circulating tumor cells: Liquid biopsy of cancer. Clin Chem 59: 110-118, 2013.

9. Nguyen DX, Bos PD and Massagué J: Metastasis: From dissemination to organ-specific colonization. Nat Rev Cancer 9: 274-284, 2009.

10. Kang Y and Pantel K: Tumor cell dissemination: Emerging biological insights from animal models and cancer patients. Cancer Cell 23: 573-581, 2013.

11. Gorges TM and Pantel K: Circulating tumor cells as therapy-related biomarkers in cancer patients. Cancer Immunol Immunother 62: 931-939, 2013.

12. Lianidou ES, Markou A and Strati A: Molecular characterization of circulating tumor cells in breast cancer: Challenges and promises for individualized cancer treatment. Cancer Metastasis Rev 31: 663-671, 2012.

13. Hou JM, Greystoke A, Lancashire L, Cummings J, Ward T, Board R, Amir E, Hughes S, Krebs M, Hughes A, et al: Evaluation of circulating tumor cells and serological cell death biomarkers in small cell lung cancer patients undergoing chemotherapy. Am J Pathol 175: 808-816, 2009.

14. Krebs MG, Sloane R, Priest L, Lancashire L, Hou JM, Greystoke A, Ward TH, Ferraldeschi R, Hughes A, Clack G, et al: Evaluation and prognostic significance of circulating tumor cells in patients with non-small-cell lung cancer. J Clin Oncol 29: 1556-1563, 2011.

15. Cristofanilli M, Budd GT, Ellis MJ, Stopeck A, Matera J, Miller MC, Reuben JM, Doyle GV, Allard WJ, Terstappen LW, et al: Circulating tumor cells, disease progression, and survival in metastatic breast cancer. N Engl J Med 351: 781-791, 2004.

16. Hayes DF, Cristofanilli M, Budd GT, Ellis MJ, Stopeck A, Miller MC, Matera J, Allard WJ, Doyle GV and Terstappen LW: Circulating tumor cells at each follow-up time point during therapy of metastatic breast cancer patients predict progression-free and overall survival. Clin Cancer Res 12: 4218-4224, 2006.

17. Cohen SJ, Punt CJ, Iannotti N, Saidman BH, Sabbath KD, Gabrail NY, Picus J, Morse M, Mitchell E, Miller MC, et al: Relationship of circulating tumor cells to tumor response, progression-free survival, and overall survival in patients with metastatic colorectal cancer. J Clin Oncol 26: 3213-3221, 2008.

18. de Bono JS, Scher HI, Montgomery RB, Parker C, Miller MC, Tissing H, Doyle GV, Terstappen LW, Pienta KJ and Raghavan D: Circulating tumor cells predict survival benefit from treatment in metastatic castration-resistant prostate cancer. Clin Cancer Res 14: 6302-6309, 2008.
19. Pantel K, Brakenhoff RH and Brandt B: Detection, clinical relevance and specific biological properties of disseminating tumour cells. Nat Rev Cancer 8: 329-340, 2008.

20. Cristofanilli M: Circulating tumor cells, disease progression, and survival in metastatic breast cancer. Semin Oncol 33 (Suppl 9): S9-S14, 2006

21. Xu KC, Niu LZ, He WB, Hu YZ and Zuo JS: Percutaneous cryosurgery for the treatment of hepatic colorectal metastases. World $\mathrm{J}$ Gastroenterol 14: 1430-1436, 2008.

22. Niu LZ, Li JL and Xu KC: Percutaneous cryoablation for liver cancer. J Clin Transl Hepatol 2: 182-188, 2014.

23. Lin $\mathrm{CH}$, Chao LK, Hung PH and Chen YJ: EGCG inhibits the growth and tumorigenicity of nasopharyngeal tumor-initiating cells through attenuation of STAT3 activation. Int J Clin Exp Pathol 7: 2372-2381, 2014.

24. Hussein YM, Ghareib AF, Mohamed RH, Radwan MI and Elsawy WH: MAGE-3 and MAGE-4 genes as possible markers for early detection of metastases in hepatitis C virus Egyptian patients complicated by hepatocellular carcinoma. Med Oncol 29: 994-999, 2012.

25. Hu Y, Fan L, Zheng J, Cui R, Liu W, He Y, Li X and Huang S: Detection of circulating tumor cells in breast cancer patients utilizing multiparameter flow cytometry and assessment of the prognosis of patients in different CTCs levels. Cytometry A 77: 213-219, 2010.

26. Kodera Y, Nakanishi H, Ito S, Yamamura Y, Kanemitsu Y, Shimizu Y, Hirai T, Yasui K, Kato T and Tatematsu M: Quantitative detection of disseminated free cancer cells in peritoneal washes with real-time reverse transcriptase-polymerase chain reaction: A sensitive predictor of outcome for patients with gastric carcinoma. Ann Surg 235: 499-506, 2002.

27. Livak KJ and Schmittgen TD: Analysis of relative gene expression data using real-time quantitative PCR and the $2^{-\Delta \Delta C T}$ method. Methods 25: 402-408, 2001.

28. Poon RT and Fan ST: Hepatectomy for hepatocellular carcinoma: Patient selection and postoperative outcome. Liver Transpl 10 (Suppl 1): S39-S45, 2004.

29. Ng KK, Lo CM, Chan SC, Chok KS, Cheung TT and Fan ST: Liver transplantation for hepatocellular carcinoma: The Hong Kong experience. J Hepatobiliary Pancreat Sci 17: 548-554, 2010.

30. Gutman S and Kessler LG: The US Food and Drug Administration perspective on cancer biomarker development. Nat Rev Cancer 6: 565-571, 2006.

31. Soresi M, Magliarisi C, Campagna P, Leto G, Bonfissuto G, Riili A, Carroccio A, Sesti R, Tripi S and Montalto G: Usefulness of alpha-fetoprotein in the diagnosis of hepatocellular carcinoma. Anticancer Res 23: 1747-1753, 2003.

32. Sanai FM, Sobki S, Bzeizi KI, Shaikh SA, Alswat K, Al-Hamoudi W, Almadi M, Al Saif F and Abdo AA: Assessment of alpha-fetoprotein in the diagnosis of hepatocellular carcinoma in Middle Eastern patients. Dig Dis Sci 55: 3568-3575, 2010.

33. Saad F and Pantel K: The current role of circulating tumor cells in the diagnosis and management of bone metastases in advanced prostate cancer. Future Oncol 8: 321-331, 2012.

34. Franke WW, Schmid E, Osborn M and Weber K: Intermediatesized filaments of human endothelial cells. J Cell Biol 81: 570-580, 1979.

35. Kakehashi A, Kato A, Inoue M, Ishii N, Okazaki E, Wei M, Tachibana T and Wanibuchi H: Cytokeratin 8/18 as a new marker of mouse liver preneoplastic lesions. Toxicol Appl Pharmacol 242: 47-55, 2010

36. Tsuchiya K, Komuta M, Yasui Y, Tamaki N, Hosokawa T, Ueda K, Kuzuya T, Itakura J, Nakanishi H, Takahashi Y, et al: Expression of keratin 19 is related to high recurrence of hepatocellular carcinoma after radiofrequency ablation. Oncology 80: 278-288, 2011.

37. Racila E, Euhus D, Weiss AJ, Rao C, McConnell J, Terstappen LW and Uhr JW: Detection and characterization of carcinoma cells in the blood. Proc Natl Acad Sci USA 95: 4589-4594, 1998.

38. Pachmann K, Heiss P, Demel U and Tilz G: Detection and quantification of small numbers of circulating tumour cells in peripheral blood using laser scanning cytometer (LSC). Clin Chem Lab Med 39: 811-817, 2001.

39. Whiteside TL: What are regulatory $\mathrm{T}$ cells (Treg) regulating in cancer and why? Semin Cancer Biol 22: 327-334, 2012.

40. Misao A, Sakata K, Saji S and Kunieda T: Late appearance of resistance to tumor rechallenge following cryosurgery. A study in an experimental mammary tumor of the rat. Cryobiology 18: 386-389, 1981. 